\title{
Problems of Assessment and Implementation of Digital Transformation in the System of State and Municipal Government of Russia
}

\author{
Boris Pedanov ${ }^{1, *}$ \\ ${ }^{1}$ Department of State and Municipal Administration, Kuban State University, Krasnodar, Russia \\ *Corresponding author. Email: bbp02@mail.ru
}

\begin{abstract}
The article is devoted to the increasing role of digitalization in improving the country's competitiveness, which reflects the most promising trends in the development of the economy, social sphere and management system. The development of digital economy cannot be imagined without the formation and continuous improvement of e-government. The transformation should cover all levels of the state and municipal management system. Currently, this process is being implemented at different speeds, and there is a significant lag at the local government level. Issues of digital transformation of local selfgovernment are currently becoming particularly important.
\end{abstract}

\section{Keywords: digital transformation, innovative technologies, system of state and municipal government}

\section{INTRODUCTION}

At the present stage of development of economic relations and technological processes, digitalization should be considered as one of the priority factors for improving the country's competitiveness, which reflects the most promising trends in the development of the economy, social sphere and management system. The transformation of any system is not possible without assessing the current state and forecasting the most probable trends and development opportunities. In respect to the sphere being studied, this process is complicated by the complexity of defining a specific list of criteria and indicators of the digital economy and the lack of a unified approach to the interpretation of its content.

As defined by the World Bank, the digital economy is a system of economic, social and cultural relations based on the use of digital information and communication technologies to create a new knowledge-based economic model. This leads to the emergence of new digital competencies in business, government, and society [1].

According to the interpretation of the largest consulting company Deloitte, the digital economy should be considered as a type of economic activity, the development source of which is a lot of examples of networking cooperation of individuals, firms, technical devices and processes. The most important characteristic of the digital economy is hyperconnectivity, which reflects the intensification of relationships between people, enterprises and technology due to the development of the Internet and mobile technologies [2].

In Russia, the basic interpretation of the digital economy can be called the definition presented in the Strategy of the Information Society Development in the Russian Federation for 2017-2030, according to which it is understood as an economic activity, in which the most important production factor is information in digital form [3]. The analysis of large amounts of data and the use of its results should significantly improve the efficiency of production activities, the adoption and application of technologies, storage, sale and delivery of goods as well as the provision of services.

For the purposes of statistical survey, the digital economy should be considered as a set of interrelated processes for creating, processing, storing, transmitting and using information for the production of goods and services based on digital technologies.

Different countries use extremely different methods to assess the dynamics of digital transformation. These methods reflect national particularities of economic processes, the level of technological development, and the selected priorities of implemented programs and projects for the development and introduction of innovations based on information and telecommunications technologies. Comparing the dynamics of different countries in this area has made it necessary to form unified approaches to the study of transformations for the construction and development of the digital economy. 


\section{APPROACHES TO ASSESSING THE LEVEL OF DIGITALIZATION AND THE DYNAMICS OF THE ADOPTION OF INNOVATIVE TECHNOLOGIES IN THE ECONOMY AND MANAGEMENT}

Currently, a wide list of ratings has been formed and continues to be improved to compare countries in terms of the level of digitalization and innovative technologies adoption dynamics in various spheres of society.

One of the most frequently mentioned ratings is the International Digital Economy and Society Index, which is calculated by Directorate-General for Communications Networks, Content and Technology of the European Union. In 2016, Russia ranked 37th out of 45 analyzed countries [4]. Unfortunately, in the following years, the analysis was conducted only for the member countries of the European Union, that does not allow us to track the dynamics of Russia in this rating.

In 2019, Russia rose to 38th place in the rating of digital competitiveness of major economies, which is compiled by analysts of the Swiss business school IMD [5]. In total, the rating includes 63 countries. A fairly broad list of 50 criteria was used for evaluation. These criteria were grouped into three blocks - knowledge, technology, and readiness for the future. With that, the top three places in this rating were taken by such countries such the United States, Singapore and Sweden.

It should be noted that in 2017, Russia dropped to 45th place in the ICT Development Index (IDI), while in 2016, Russia took 43rd place in it. This was despite an increase in the value of the Russian index, as other participants showed more noticeable growth.

The researches based on surveys of users of information and communication technologies take special place. Every year, a communication holding company Dentsu Aegis Network Russia together with the Oxford Economics consulting Agency conduct a study that results in the formation of the Digital Society Index. In the process of the index calculation, such indicators as dynamicity (how much the digital economy affects growth), the level of digital technologies availability (the scale of development), and trust (how markets strengthen credibility of the digital economy) are taken into account.

In the course of the study in 2019, experts interviewed more than 43 thousand people and Russia took the 23rd place in this rating [6]. In the previous version of the rating, it was in the tenth place. The developers of this index noted that primary reason of Russia's decline by 13 positions was in the fact that in 2019 the number of countries in which the study was conducted increased from 10 to 24 . When assessing the satisfaction of digital needs of the population, the researchers concluded that the basic digital needs in Russia are met by $37 \%$. The basic needs stand for the access to the Internet and mobile communications, as well as credibility in using personal data. For comparison, in China, this figure reaches $69 \%$, and in India $-67 \%$ and these are the highest values in the list. The global average is $49 \%$. At the same time, $58 \%$ of respondents in Russia reported satisfaction of psychological wants. Here we are talking about the impact of digital technologies on health and personal well-being. The global average is $38 \%$, and Russia has the highest rate among the countries studied.

$48 \%$ of the survey participants reported satisfaction with digital needs for self-development in Russia. The need for self-development is the availability of skills, education and job search opportunities. The global average of this indicator is $45 \%$, in India it is $69 \%$, and in Mexico - $66 \%$. As for special needs, the level of satisfaction in Russia is also $48 \%$. Special needs refers to respondents' assessment of the possibility of influencing society through technologies and solving world problems with their help.

The average value of the indicator in the world reaches $49 \%$. In China, it is $76 \%$, and in India - 74\%. It can be noted that the lowest rating among respondents in our country was the satisfaction of the population digital needs (access to the Internet and mobile communications, as well as the credibility of using personal data), which contrasts with the assessment of this indicator using the methods of other ratings.

Most of the ratings are quite subjective though they provide a certain basis for comparing different countries. When analyzing key indicators that affect the ranking, these ratings can help to identify the lagging and most problematic areas.

The development of digital economy cannot be imagined without the formation and continuous improvement of e-government. It can be interpreted as a new form of organizing the activities of public authorities, which provides a whole new level of efficiency and convenience for organizations and citizens to receive public services and information on the results of public authorities' activities through the widespread use of information and communication technologies [7].

It also should be emphasized that e-government is not to be considered as a supplement or analogue of traditional government, but rather a new way of interaction based on the active use of information and communication technologies in order to improve the efficiency of the state and municipal administration system by increasing transparency, accessibility and speed of implementation of procedures. The adoption of new technologies in the system of state and municipal administration reduces costs on the one hand, and on 
the other hand it facilitates the receiving of services, while minimizing direct contact of the population with the authorities.

The term "e-government" is most likely to be a temporary one and it will disappear as soon as the decision-making and service delivery processes in the state and municipal administration system are fully implemented by electronic means.

First of all, the biannual e-government development index (EGDI) is used to compare the success of different countries in this area. This rating is calculated on the basis of three indicators for each country: the development of electronic services, the development of human capital and the development of telecommunications infrastructure over the two years preceding the rating update. In 2020, Russia ranked 36th in this rating, which is four positions lower than the results of two years earlier [8].

In terms of the development of E-participation, Russia ranked 27th in 2020, against 23rd place in 2018. This means a decrease in the level of involvement of citizens in the decision-making process, and a decrease in the transparency and openness of the state bodies activities. Despite the obvious success in converting the process of providing state and municipal services to electronic form, there are still many problems.

In the course of monitoring the quality of state and municipal services provided in electronic form, conducted by the Ministry of Economic Development of the Russian Federation in 2019, 1,336 priority services in 85 territorial entities of the Russian Federation were studied. As a result, the application was submitted for 1120 services, which makes $84 \%$ of the total number of services studied [9]. At the same time, almost half of the submitted applications were left without consideration and response.

During monitoring, it became obvious that in some cases the description of priority regional and municipal services on portals does not provide applicants with complete and reliable information. Government agencies may post either insufficient information (for example, they do not specify all the documents required to receive a service) or outdated information that does not correspond to the current versions of legal acts regulating the provision of services. Thus, $14 \%$ of the necessary information is not provided on the Unified Portal of Public and Municipal Services, while about $40 \%$ of the information is unreliable. It should be noted that the Krasnodar Region is not among the leaders of this rating, it takes 38 th place (43 points out of 120 maximum possible). It is obvious that the leader of this rating was Moscow with 98 points.

Most of the technical problems that were noticeable a few years ago in the work of portals of state and municipal services, as well as portals of separate departments, have been resolved. Failures are the result of peak loads, for example, registration of a one-time payment for children at the federal level or passes for traveling by car during quarantine in Moscow.

\section{SPECIFICS AND PROBLEMS OF DIGITAL TRANSFORMATION AT VARIOUS LEVELS OF THE SYSTEM OF STATE AND MUNICIPAL GOVERNMENT}

For the first time in our country, the target for the formation of e-government was declared as early as 2003. Initially, the short-term goal was to create a kind of "information board", through which it would be easy to get information about all services provided by the authorities, where and how they can be obtained. In the following years, the state's policy in the development of information technologies was not fully consistent, the priorities changed regularly. In particular, egovernment, digital signature (e-signature), trusted third party, information society, provision of state and municipal services in electronic form, interdepartmental information interaction in electronic form came to the fore.

It is planned that by 2024 , Russia will have an information platform through which almost all state procedures and provided services to be available in electronic form without visiting agencies and submitting hard copy documents. Citizens' satisfaction with the work of civil servants will have to grow to $80 \%$ [10]. Achieving these goals will allow us to talk about the formation of e-government that meets the requirements of the modern digital economy.

During the audit, Accounts Chamber of the Russian Federation was not able to fully assess the costs of converting the process of providing public services to electronic form. According to approximate calculations, in 2017-2019 alone, these expenses amounted to 60-75 billion rubles, including the cost of data processing centers and e-government infrastructure. The costs for creating a system of monitoring the use of information and communication technologies in the activities of Federal government agencies have raised a large number of questions. Experts of the Accounts Chamber did not find evidence of creation of such a system and its successful operation.

The Accounts Chamber of the Russian Federation conducted a study to form a rating of state information systems by the level of information availability and the quality of data presented in them. In the process of compiling the rating, its authors selected 50 systems with most socially significant information for disclosure out of 876 federal state information systems that exist in Russia according to the Federal state information system for coordination of informatization. 
Each federal state information system was evaluated by experts by 12 attributes that allow them to find out whether these systems have such characteristics as openness and availability of information, including information about the purpose of creating the system, its operator, functions performed, expenditures for creation, development and operation; availability and quality of open data that can be used to create public goods as well as for commercial or research purposes; opportunities and conditions to integrate with other state information systems for expeditious obtaining or transmission of information in the "system-to-system" mode.

Only eight information systems of the rating were classified as systems with a high degree of openness, in particular, the Federal state information system of the State Catalogue of the Museum Fund of the Russian Federation; the Electronic Budget Integrated Information System for Public Finance Management; Unified Information System of Procurement (UISP); Portal of State and Municipal Institutions; Federal Information Address System; the Internet Portal for the Promotion of Cultural Heritage and Traditions of Russia; Unified State Register of Cultural Heritage; the Open Data Portal of the Ministry of Culture [11]. The remaining systems were divided into categories with medium, insignificant and low levels of openness, as well as with complete and almost complete data inaccessibility.

By the opinion of many experts, a serious problem of digital transformation of public administration in Russia can be considered in the fact that the authorities are still implementing IT solutions created for themselves and convenient for officials, not those which are really in demand by the market, business and citizens.

The transformation should cover all levels of the state and municipal management system. Currently, this process is being implemented at different speeds, and there is a significant lag at the local government level. Issues of digital transformation of local selfgovernment are currently becoming particularly important. On the one hand, this is directly related to the digital paradigm of development of the economy, management system and society as a whole. On the other hand, this is due to the need for municipal administration to participate in the implementation of national projects, the results of which should be evident in each territorial entity and municipality.

The insufficient level of digital technologies adoption at the local level is influenced by a range of factors and trends. Some of them are typical for the system of state and municipal administration as a whole, while others are more specific at the local level. The most noticeable global problems are such issues as digital security, first of all, the security of personal data and unwillingness of a part of the population to accept new ways of communication and receive state and municipal services in electronic form. As the experience of the most high-profile cases of personal data theft shows, the main problems are not related to the technological component, but to the human factor.

The unwillingness of people, usually older generation, to use new forms of digital interaction is not so much due to the lack of technical capabilities, but rather the need to develop new skills and competencies. It is impossible to solve this problem without implementing a large-scale program to improve digital literacy, which should focus on the convenience of new ways of interaction.

Problems that are more typical for the local level include both traditional ones - insufficient funding and lack of highly qualified specialists, and more specific ones - duplication of actions (often it is necessary to maintain both electronic and hard-copy document workflow) and fragmentation of digital infrastructure (different software or technical equipment as a result of upgrading or compliance with import substitution requirements).

Often, decisions initiated by state authorities do not fully take into account the interests and specifics of the functioning of local self-government bodies. More than $90 \%$ of Russian municipalities are forced to participate in the process of digital transformation in conditions of insufficient funding [12]. In the context of budget deficit, municipalities do not have enough funds and personnel with the necessary experience and qualifications to resolve issues related to the digitalization of their working processes. The level of software import substitution in Russian government bodies in 2019 decreased for the first time - to $55 \%$ from $62.2 \%$ of a previous year, despite the presence of strictly regulated indicators for its increase.

Despite constant funding deficit in the sphere of digital transformation it is possible to note some positive results. In particular, automated information systems and information resources on priority directions of municipalities activities that could become the prototype for the model solutions have been created; specialized departments responsible for issues of digital transformation have been created and successfully operated in the most part of cities; focusing on information systems for local governments appeared among software developers. The above mentioned achievements characterize the situation in large donor cities. At the same time, the gap in the sphere of informatization between them and subsidized municipalities, primarily small rural settlements, continues to increase.

For comprehensive and consistent implementation of digital technologies adoption process in municipal 
management, it is necessary to teach municipalities to work with data and extract maximum benefits from it to improve the quality and standard of living of citizens. As a positive example in this area, we can mention the Lean smart city project, implemented by Rosatom Corporation together with a number of city administrations. The technologies used in this project are aimed at improving the quality and efficiency of management processes in the urban economy by minimizing errors and reducing the time of different processes implementation, optimal use of resources and involving residents in solving issues directly related to the life of the municipality through the use of digital tools for data collection and analysis.

An example of improving the efficiency of interaction between the population and local authorities is the Dobrodel portal, which provides residents of the Moscow region with opportunities to interact with authorities and solve specific problems, make proposals without submitting documents in hard copies. The functioning of the Dobrodel portal is based on the fact that registered users can report on business problems, express gratitude, make suggestions, and perform a number of other actions, including using a mobile application.

The portal "Dobrodel" is an analog of the portal "Our City", which operates in Moscow, where residents can leave an appeal on almost all issues of their concern. In 2018, the number of registered users of the portal "Dobrodel" was more than 800 thousand, in 2019 more than 1.5 million. At the same time, the number of new users registering weekly on the Dobrodel portal in 2019 is almost three times higher than the same indicator in the previous year. In 2019, the number of submitted complaints exceeded 3.6 million, and more than 1.2 million problems were resolved [13].

It is particularly necessary to emphasize the lack of attention paid to the development of a culture of interaction in digital society. Information culture in a broad sense can be interpreted as the ability to work purposefully with information and use it to receive, process and transmit a computer information technology, modern technical means and methods.

In practice, we often encounter examples of how representatives of regional and local authorities by their behavior or statements damage the image of the management system as a whole. All people tend to make mistakes, which can be compounded by a sense of impersonality of such communication. However, the actions of state and municipal employees cause the most noticeable public response. Those issues that previously would have remained a local problem, now they often get in the information agenda at the country level as a whole due to the variety of information distribution channels (social networks, YouTube). Thus, the cost of an error in modern conditions increases.
Despite the fact that digital transformation at the local level is accompanied by a large number of problems, it is possible to identify factors for positive forecasts. In 2018, the United Nations Department of Economic and Social Affairs (UN DESA) calculated a local index of online services to assess the development of e-government at the municipal level. Among the 40 cities studied, usually the capitals or largest cities of the most developed countries, Moscow took the first place [14]. Moscow is a federal territorial entity which has financial and organizational capabilities that are not comparable to municipalities. But the presence of such a benchmark can also contribute to successful digital transformation at the local level.

\section{CONCLUSION}

In order to achieve a fundamentally new level of quality of state and municipal management, it is necessary to rethink approaches to the organizational and functional structures of administrating authorities, formation of unified digital information platforms, formation and development of new digital competencies for officials at all levels and links of the management system.

Factors that increase the effectiveness of digital transformation include the formation of a digital strategy and the identification of digital transformation managers at all levels of management, clear designation of responsibility areas and the exclusion of duplicate functions and procedures, optimization of existing organizational mechanisms, competent selection of a digital team to launch the processes of creating and developing digital products and services (from the stage of generating ideas to the first pilots and further replication).

To reduce current costs, it is advisable to intensify the transition from the existing software and hardware infrastructure with proprietary software to a virtual environment based on Russian-made software or open source software distributed freely, as well as the introduction of cloud technologies that have proven their effectiveness in the private sector.

\section{References}

[1] Report about the development of the digital economy in Russia [Electronic resource]. - URL: https://openknowledge.worldbank.org/bitstream/handle/10986/3 0584/AUS0000158-RU.pdf? sequence $=4$

[2] What is digital economy? [Electronic resource]. - URL: https://www2.deloitte.com/mt/en/pages/technology/articles/mtwhat-is-digital-economy.html

[3] On the Strategy for the Development of the Information Society in the Russian Federation for $2017-2030$. Decree of the President of the Russian Federation No. 203 dated May 9, 2017 [Electronic resource]. - URL: https://www.garant.ru/products/ipo/prime/doc/71570570 
[4] The Digital Economy and Society Index (DESI) 2016 [Electronic resource]. - URL: https://ec.europa.eu/digital-singlemarket/en/desi

[5] Digital competitiveness ranking [Electronic resource]. - URL: https://www.imd.org/dtp/digital-technology-transformationprograms

[6] Digital society index 2019: Human needs in a digital world [Electronic resource]. https://www.oxfordeconomics.com/publication/download/3145 06

[7] On the approval of the state program of the Russian Federation "Information Society". Resolution of the Government of the Russian Federation No. 313 dated April 12, 2014 [Electronic resource]. - URL: http://www.consultant.ru/document/cons_doc_LAW_162184

[8] United Nations E-Government Survey 2020 [Electronic https://www.un.org/development/desa/publications/publication/ 2020-united-nations-e-government-survey

[9] Monitoring the quality of the translation of public services into electronic form [Electronic resource]. - URL:

[10] https://www.economy.gov.ru/material/news/minekonomrazvitiy a_podvelo_itogi_ezhegodnogo_monitoringa_kachestva_perevo da_gosudarstvennyh_uslug_v_elektronnuyu_formu.html

[11] Introduced the concept of Service State version 2.0. [Electronic resource]. - URL: https://digital.gov.ru/ru/events/38530

[12] Assessment of the openness of state information systems in Russia. Analytical report of the Accounts Chamber of the Russian Federation [Electronic resource]. - URL: https://cpur.ru/new-research/state-openness-gis/

[13] A. Y. Gubov, Ways of digital transformation of local governments, Method, 2019, vol.3, pp. 2-5.

[14] Digital Economy Indicators 2019: statistical compilation [Electronic r resource]. https://www.hse.ru/data/2019/06/25/1490054019/ice2019.pdf 